\title{
A Wideband Rectenna Using High Gain Fractal Planar Monopole Antenna Array for RF Energy Scavenging
}

\author{
Mohammad M. Fakharian (i) \\ Faculty of Engineering, University of Garmsar, P.O. Box 3581755796, Garmsar, Iran \\ Correspondence should be addressed to Mohammad M. Fakharian; mmfakharian@ugsr.ir
}

Received 26 March 2020; Accepted 29 May 2020; Published 25 June 2020

Academic Editor: Ananda S. Mohan

Copyright (c) 2020 Mohammad M. Fakharian. This is an open access article distributed under the Creative Commons Attribution License, which permits unrestricted use, distribution, and reproduction in any medium, provided the original work is properly cited.

\begin{abstract}
This paper introduces a wideband rectenna that can scavenge ambient wireless power to a range of frequency band from $0.91 \mathrm{GHz}$ to $2.55 \mathrm{GHz}$ efficiently. The proposed rectenna is based on a wideband $2 \times 2$ fractal monopole antenna array with omnidirectional radiation patterns and high gains of 5 to $8.3 \mathrm{dBi}$ at the desired bands. An improved two-branch impedance matching technique is presented which is designed to enhance the rectifier circuit performance with a relatively low input power ranging from $-25 \mathrm{dBm}$ to $10 \mathrm{dBm}$. Also, a full-wave wideband rectifier that can suitably improve the RF-to-DC power conversion efficiency is designed for the rectenna. A peak efficiency of $76 \%, 71 \%, 61 \%$, and $62 \%$ is obtained at $950,1850,2100$, and $2450 \mathrm{MHz}$, respectively. Measurement results show that a conversion efficiency of $68 \%$ has been achieved over an optimal $4.7 \mathrm{k} \Omega$ resistor when the simultaneous four-band input power level is $-10 \mathrm{dBm}$. Moreover, an output DC voltage of around $243 \mathrm{mV}$ with voltage varying within $160-250 \mathrm{mV}$ can be achieved by gathering the low ambient wireless power inside laboratory. This study proves that the proposed rectenna can be applied to a range of many low-power electronic applications.
\end{abstract}

\section{Introduction}

With the rapid development of wireless systems, the ambient radio frequency $(\mathrm{RF})$ energy is increasing from several of electromagnetic power sources around the world, such as the mobile telephones, mobile base stations, television/radio broadcast stations, and Wi-Fi routers. Despite these ambient electromagnetic sources, an RF energy scavenging system is one of the most desirable technologies for steady charging of low-power electronic devices, because that could omit the requirement for a battery overall and save maintenance cost [1]. The RF energy harvesting by technologies of rectifying antenna (rectenna) is a practicable solution to convert the ambient wireless power to DC power.

To maximize harvested RF energy in the rectenna, the antenna in this system should be able to receive high RF energy from multiple frequencies at any directions in the environment. Thus, the antenna should be of wideband operational frequency and omnidirectional radiation pattern. Moreover, since the power density of RF signals and its levels in the ambience are almost weak [2], it is essential to design antenna array consisting of more elements with higher gain to take enough power to reach optimal input power. However, designing a wideband high gain rectenna is very challenging, due to the nonlinearity behaviour of the rectifier. It has been proven that the input impedance of the rectifying circuit differs in terms of input power level, frequency, and also load impedance [3]. So far, several techniques have been presented for multiband $[4,5]$ or wideband [6-11] rectenna designing but there are various limitations. As already mentioned in [12], wideband antennas are desirable rather than multiband antennas, because they have easier design, and they are interoperable among countries, whose assignment plans of frequency can be diverse among them. So, this paper focused on the wideband rectenna.

In [6], a wideband bent triangular omnidirectional antenna with both horizontal and vertical polarized waves is proposed for scavenging from 0.85 to $1.94 \mathrm{GHz}$, but the bandwidth is not enough for energy harvesting applications and the realized gain is relatively low. In [7], a broadband 
dual-polarized cross-dipole antenna with a broadband rectifying circuit with a two-branch impedance matching circuit is proposed for ambient wireless signals with a lowpower density from 1.8 to $2.5 \mathrm{GHz}$. In [8], a wideband rectifier array associated with a dual-polarized and differential-feed fractal slotted ground antenna for harvesting from 1.8 to $2.6 \mathrm{GHz}$ is proposed. For low incident power densities less than $200 \mu \mathrm{W} / \mathrm{cm}^{2}$, a wideband differential rectifier with an Archimedean spiral dipole antenna for harvesting from 1.2 to $5 \mathrm{GHz}$ is presented [9]. However, the achieved bandwidths for these three rectennas are not adequate for RF harvesting applications and the radiation pattern is not uniform and omnidirectional across the total band of interest. A three-dimensional (3D) stacked folded dipole array is designed for RF energy harvesting [10]. An array is also presented in [11] by a 3D 4-element Vivaldi antenna with the frequency range from $1 \mathrm{GHz}$ to $3 \mathrm{GHz}$ and rectifier circuits for energy harvesting applications. However, a 3D antenna array increases the antenna overall size, which makes the system bulky and the RF-to-DC conversion efficiency is not very high.

The overall performance of a rectenna, in addition to the antenna performance, basically depends on the RF-DC conversion efficiency of the rectifying circuit. Recently, the main challenge of RF energy harvesting is how to enhance the power conversion efficiency of the rectifying circuit at low-input power levels over a wideband frequency. An appropriate matching network is one of great importance for enhancing the performance of rectifier circuit with a fixed load resistance $[13,14]$. In order to remove the higher order harmonics generated by the nonlinear circuit and enhance the conversion efficiency, a filter between the antenna and the rectifier can be also used $[15,16]$. In $[6-10,13,17-20]$, several types of wideband rectifier circuits are presented. In the best case of input power level, the maximum reported power conversion efficiencies vary from 30 to $70 \%$. However, high efficiency designs are mostly for a relatively high input power (such as levels of $0 \mathrm{dBm}$ [17], $10 \mathrm{dBm}$ [18], $19.5 \mathrm{dBm}$ [19], and $12.8 \mathrm{dBm}$ [20]) which is not suitable for ambient energy scavenging.

In this work, we designed a monopole wideband antenna array fed by a microstrip-to-slot-line transition feeding network. The feeding network is based on slot-line stubs and radial microstrip for the realization of broadband microstrip-to-slot-line transitions [21, 22]. In the proposed antenna, compact size and wideband functions are obtained by using Koch fractal geometry and loaded slot on radiation stub. The compact structure and easy configuration are the main advantages of fractal monopole antenna [23, 24]. The loaded slot on radiation stub can also enhance the impedance bandwidth of the antenna [25]. In the following, based on [7], a full-wave Greinacher rectifying circuit with a twobranch impedance matching network is employed in the antenna to realize the broadband rectenna with low input power levels. Simulated results and experimental measurements are carried out to evaluate the performance of the proposed antenna, rectifying circuit, and rectenna, separately.

\section{Wideband Antenna Array Design}

The layout and detailed dimensions of a single monopole fractal antenna element and $2 \times 2$ array are shown in Figures 1(a) and 1(b), respectively. The antenna is proposed on a FR- 4 substrate with $\varepsilon_{\mathrm{r}}=4.4, \tan \delta=0.02$, and thickness $h=0.8 \mathrm{~mm}$. In the configuration of the single element, a modified $2^{\text {nd }}$ iteration of Koch fractal radiation patch with an embedded rectangular-shaped thin slot is fed by a $50 \Omega$ microstrip line. The ground plane is modified to partial rectangular plane to enhance the desired impedance bandwidth and omnidirectional radiation pattern characteristics as a monopole antenna. As shown in Figure 1(b), for array structure, a microstripto-slot-line transition feeding network is used. It has attractive features compared to conventional microstrip feed network such as low feeding and radiation losses, no need for impedance matching circuits, and extremely simple circuit structure which are mostly owing to the good performances of both the microstrip-slot parallel branch circuit and the slot-microstrip series branch circuit [21]. The performances of the single and array antennas are analyzed and optimized by using Ansoft HFSS full-wave simulator [26].

The design process of the proposed antenna array can be summarized as follows:

(1) Design a radiator patch with a hexagon-shaped, microstrip feed-line with $50 \Omega$ impedance, and a partial rectangular ground plane, in which monopole antenna can operate in a wideband frequency with the central frequency of $1.8 \mathrm{GHz}$ (Antenna I).

(2) Design the first and second Koch fractal iterations that are implemented to the hexagon-shaped radiator. The geometry of Koch can be produced using an ad hoc iterative function system (IFS) algorithm designated by a set of affine transformations $W$. In other words, the IFS works by applying a series of affine transformations $W$ to an elementary shape over much iteration. Various iterations of the Koch fractal are listed in Figure 2. The IFS algorithm and design rules of Koch curves in the proposed monopole antenna can be expressed symbolically as [27]

$$
\begin{aligned}
K_{n+1}= & W\left(K_{n}\right)=\bigcup_{p=1}^{4} W_{P}\left(K_{n}\right)=W_{1}\left(K_{n}\right) \cup W_{2} \\
& \left(K_{n}\right) \cup W_{3}\left(K_{n}\right) \cup W_{4}\left(K_{n}\right),
\end{aligned}
$$

where $n$ is the $n$th fractal iteration. These transformations $W$ can be considered successively to make the monopoles $K_{1}, K_{2}, \ldots, K_{n}$.

The resonant frequency of the antenna decreases with the increase in the number of iterations, although it reduces its impedance bandwidth. The perimeter length $\left(l_{\text {perim }}\right)$ and the effective area $(A)$ of the 

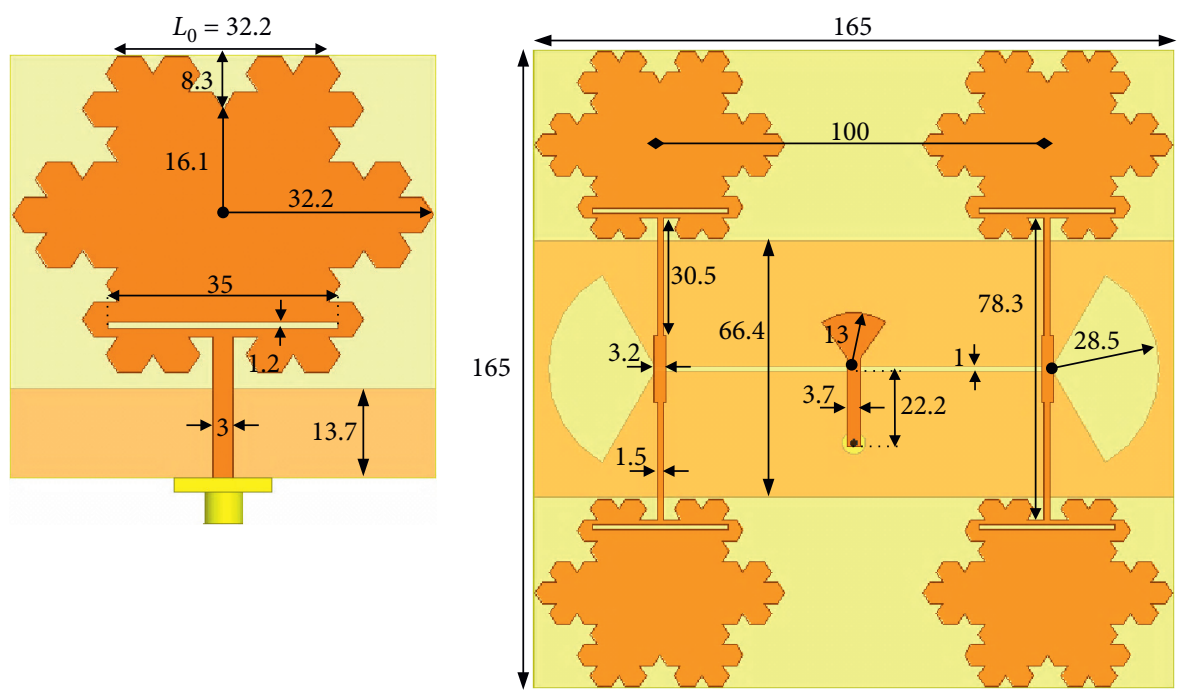

(a)

(b)

Figure 1: The layout and detailed dimensions of (a) single element and (b) the $2 \times 2$ monopole fractal antenna array (unit: mm).

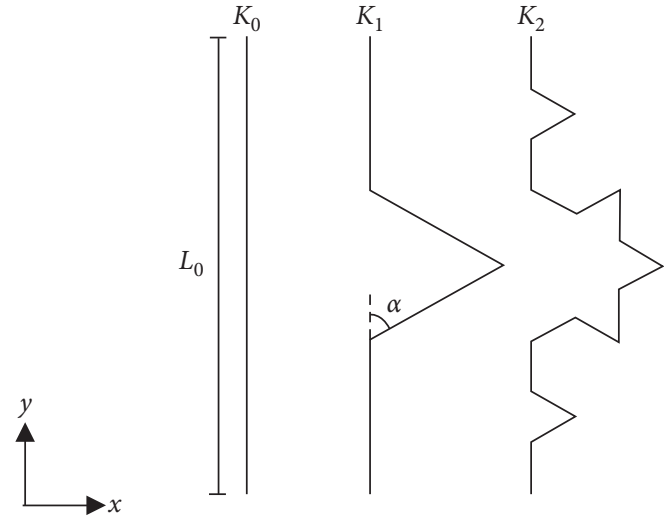

Figure 2: Koch fractal monopole from zero to second iteration.

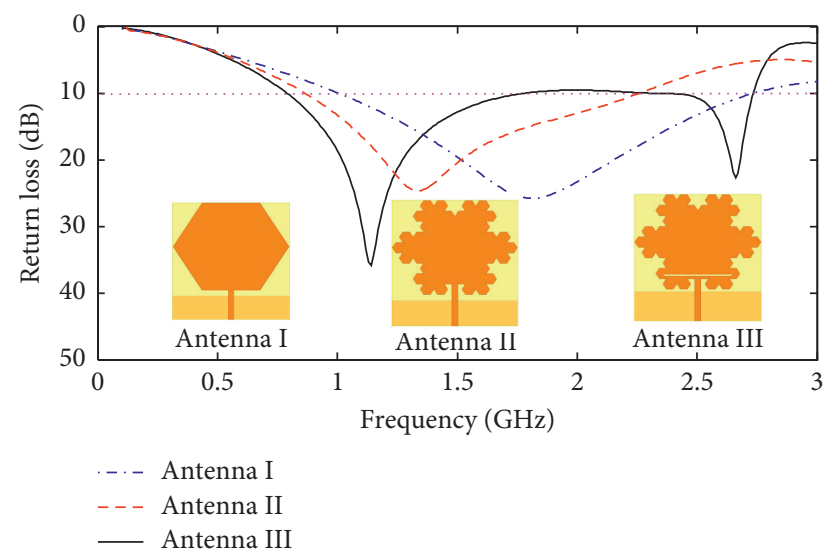

FIGURE 3: Development stages and the corresponding simulated return losses of the single antenna.

proposed modified fractal patch geometry, at indentation angle $\left(\alpha=60^{\circ}\right)$ and at iteration $n$, are found as [27]

$$
\begin{aligned}
l_{\text {perim }}(n) & =4\left[\frac{2}{3}\left(\frac{5}{3}-\cos 60\right)\right]^{n} L_{0}, \\
A(n) & =\left[1-4\left(\sum_{i=1}^{n} \frac{4^{i-1}}{9^{i}}\right) \cos 60 \sin 60\right] L_{0}^{2} .
\end{aligned}
$$

As shown in these formulas, the perimeter or the overall electrical length of the antenna increases with increasing the number of iterations so the decrease in resonant frequency stems from that. On the other hand, the enclosed area of the fractal antenna decreases with iteration increasing. Therefore, the ratio of perimeter length to enclosed area is large when more iterations are implemented in the fractal geometry, so the impedance bandwidth decreases with this extending of iteration (Antenna II).

(3) In this stage, a thin rectangular slot is applied to the fractal radiating patch. This technique increases bandwidth, especially at the end of the frequency band [25]. Indeed, this thin slot is used for the new resonance excitation function, and hence multiresonance characteristics with wider impedance bandwidth can be made. Therefore, the operating band of the antenna is improved and increased, so that it completely covers the RF energy scavenging interesting bands (Antenna III).

Based on stages 1 to 3 , the development designs of the single antenna are shown in Figure 3, and the corresponding simulated return loss curves are illustrated in the same figure.

(4) Based on the theory of microstrip-to-slot-line transition, the proposed feed network can be designed, and its structure and simulated results of 


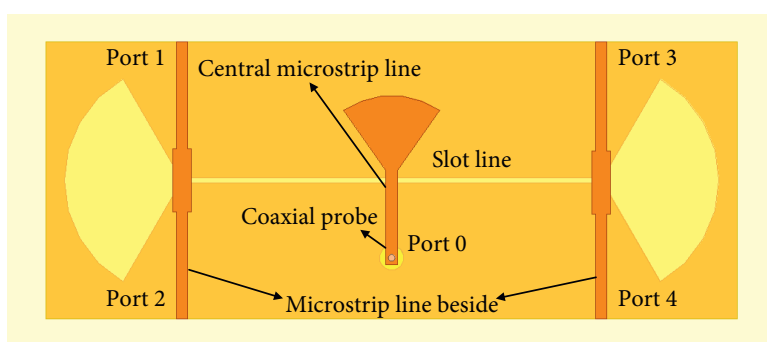

(a)

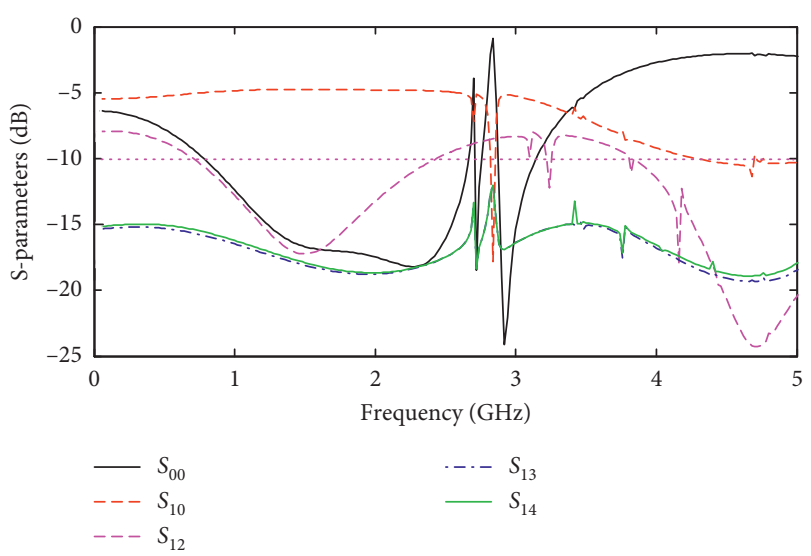

(b)

FIgURE 4: (a) Structure of the proposed feeding network. (b) The transmission $\left(S_{10}\right)$, reflection $\left(S_{00}\right)$ coefficients, and isolation between the ports $\left(S_{12}, S_{13}\right.$, and $\left.S_{14}\right)$ of the proposed network.

the design are shown in Figure 4. The feeding network contains one slot-line on the ground plane and three microstrip lines on the radiating plane. The central microstrip line is fed by a coaxial probe and slot-line is applied to transfer the input power to the two side microstrip lines. The equivalent circuits and performance mechanisms of this feeding network for maximum transmission coefficient with details are explained in $[28,29]$. The fan-shaped terminal is applied to increase the impedance bandwidth $[21,22]$. The widths of the slot-line and microstrip of the feeding network are obtained according to the input impedance of the probe and monopole antenna. Through the analysis of simulating, it can be found that the transmission coefficient is very sensitive to the slot-line width, while the effects of changing length of the side microstrip lines and space of central and beside microstrip lines on the transmission coefficient are insignificant. The reflection coefficient $\left(S_{00}\right)$, transmission coefficient $\left(S_{10}\right)$, and isolation between the ports $\left(S_{12}, S_{13}\right.$, and $\left.S_{14}\right)$ are only shown in Figure 4(b), because the magnitudes of the signal from the four output ports are the same. It is also important to note that the signal phases of port 1 with port 4 and port 2 with port 3 are consistent due to the symmetrical structure of the network. At the desired bands, the ports have isolation below $-10 \mathrm{~dB}$ and therefore each port can scavenge RF energy independently.

(5) Finally, based on the above design stages, the $2 \times 2$ antenna array is designed, and its structure is shown in Figure 1(b). In the structure, the antenna array is fed by a $50 \Omega$ coaxial probe. The spacing between elements is obtained according to both of the electromagnetic coupling and radiation performance among elements. The adopted element spacing of the array is $0.6 \lambda_{0}$ along E- and H-planes, at the central frequency of $1.8 \mathrm{GHz}$.
The proposed fractal monopole antenna array is simulated, fabricated, and measured. Figure 5 shows photographs of the fabricated prototype. The simulated and measured return loss curves of the proposed antenna array are shown in Figure 6, which appear to be in relatively good agreement. The discrepancies between the simulated data and measured results are almost due to test equipment and measurement errors. Measured result shows that the proposed fractal antenna array can cover a frequency range from 0.91 to $2.55 \mathrm{GHz}(95 \%, 10 \mathrm{~dB}$ impedance bandwidth), which is slightly lower than that of the feed network and the single monopole antenna due to the electromagnetic coupling between elements. Nevertheless, it covers the bands of most interest for RF energy harvesting application.

Figure 7 shows the measured and simulated peak gains of the array antenna in the entire band of interest. The measured gains are a little less than the simulated results, which is because of dielectric loss, the slot-line and calibration errors, and fabrication tolerance. The antenna array achieved an average gain of $6 \mathrm{dBi}$ over the operating frequency and the maximum value of $8.3 \mathrm{dBi}$ which occurs at about $0.95 \mathrm{GHz}$. It should be noted that the antenna gain is relatively high over the working band respecting the compact size and omnidirectional behaviour of the proposed antenna. Besides, the efficiency of the antenna decreases with the growth of frequency, so the value of gain reduces for higher frequencies. The following values of simulated efficiency are obtained: $82.1 \%, 76.1 \%$, and $72.4 \%$ at $0.95 \mathrm{GHz}, 1.85 \mathrm{GHz}$, and $2.45 \mathrm{GHz}$, respectively.

The measured radiation patterns along $\mathrm{H}(x-z)$ and $\mathrm{E}(y$ $z$ ) planes for three different frequencies of $0.95,1.85$, and $2.45 \mathrm{GHz}$ are presented in Figure 8. As seen in this figure, the radiation patterns are nearly stable and uniform at the different frequencies. In addition, it is also found that the antenna maintains omnidirectional pattern in the E-pane and bidirectional pattern in the $\mathrm{H}$-plane over the frequency band. The increase in cross-polarization level at low 


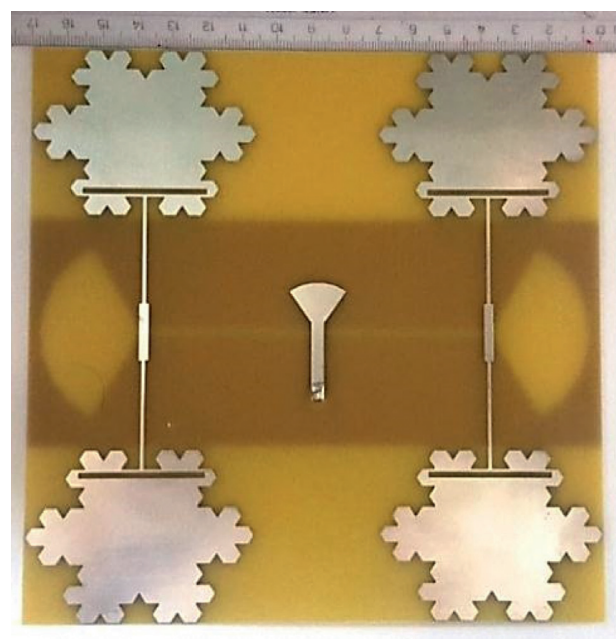

(a)

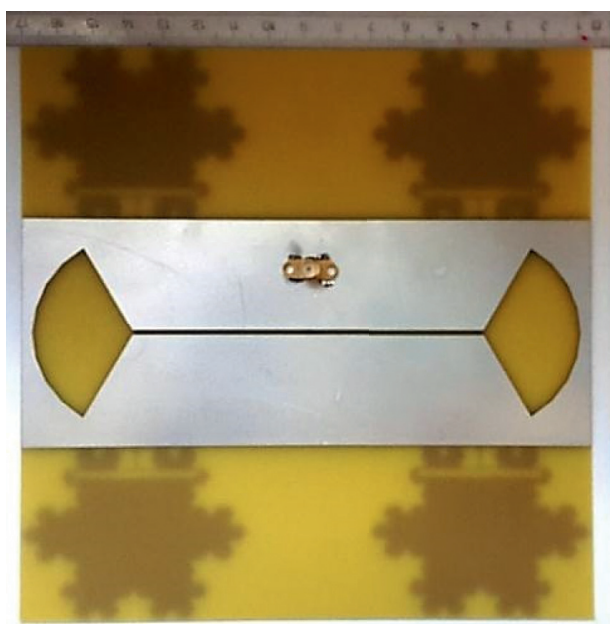

(b)

Figure 5: Prototype of the fractal monopole antenna array. (a) Top view. (b) Bottom view.

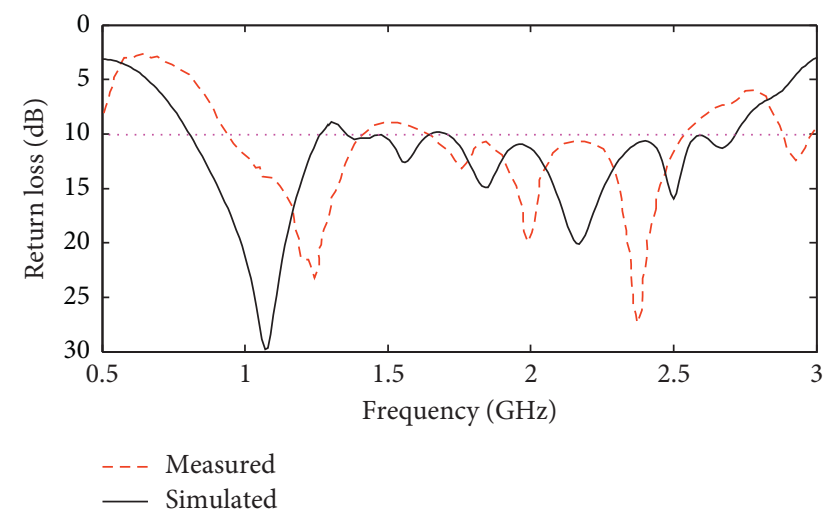

FIGURE 6: Simulated and measured return loss of the proposed antenna array.

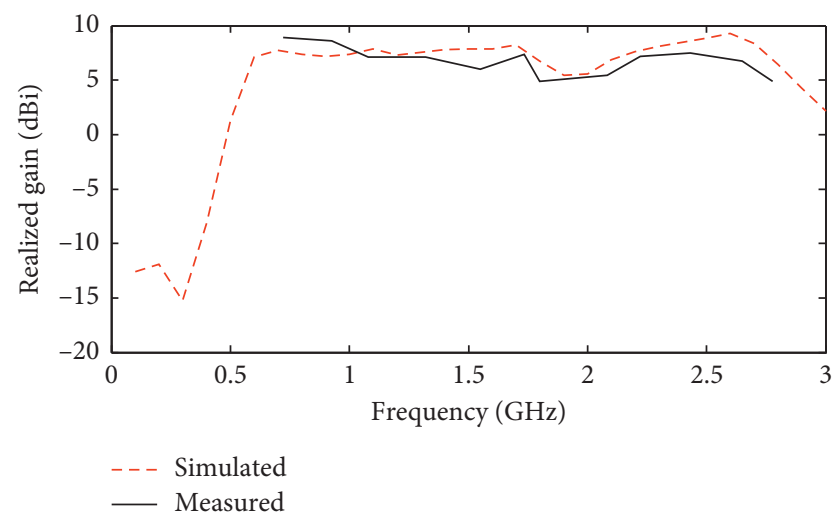

Figure 7: Simulated and measured peak gain of the proposed antenna array.

frequencies is almost by reason of hybrid current distribution excitation on the antenna radiator patch. Moreover, the side-lobes appear at high frequencies, because of the spacing between elements is very large for high frequencies.

\section{Wideband Rectifier Design}

The rectifying is a nonlinear circuit that mostly contains an impedance matching circuit for delivering the maximum power at the selected frequencies, rectifying elements to make the RF-to-DC conversion, a DC low pass filter for smoothing the ripple and storing of output DC, and a resistor load. So far, different kinds of rectifier topologies are introduced to convert the harvested wireless power to DC power [30].

The schematic of the proposed RF-to-DC circuit is shown in Figure 9 that is based on [7,20]. The RF-DC circuit contains a symmetric adjusted version of a single stage Greinacher rectifier. The Greinacher is a full-wave rectifier with high sensitivity and RF-DC conversion efficiency that is equivalent to a voltage doubler circuit with two stages that formed in a bridge type [7]. There are two branches in the rectifier with two zero-bias low-barrier Schottky diodes in each branch. The series-mounted Schottky diode HSMS285C from Avago is used for the rectifier circuit owing to its low turn-on voltage condition and small junction capacitance for a low input signal (forward bias voltage: $150 \mathrm{mV}$ at $0.1 \mathrm{~mA}$ and a junction capacitance $C_{j 0}$ of $0.17 \mathrm{pF}$ ) [31].

Scavenging in a wideband operation needs the use of a rectifier circuit with operating in a wideband frequency. For this purpose, design of the matching circuit is not easy since the rectifier circuit has complex input impedance that differs with input power level, frequency, built-in characteristics of the Schottky diode, and resistance load [3]. In our layout as seen in Figure 9, a wideband two-branch matching network is accomplished and designed through the insertion of an optimized coupled line with one shorted end stub before each of the divider branches as [20]. The coupled line can be employed to realize wideband impedance transformation. Actually, it can produce impedance matching at multiple frequencies that can tune it to realize wideband matching [20]. To combine two branches, an optimized T-junction power divider is applied as seen in [32]. One of the benefits 


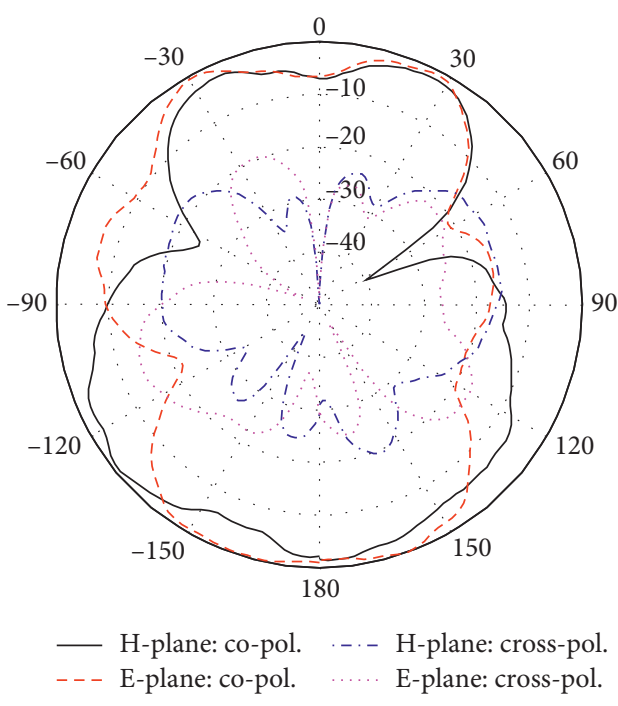

(a)

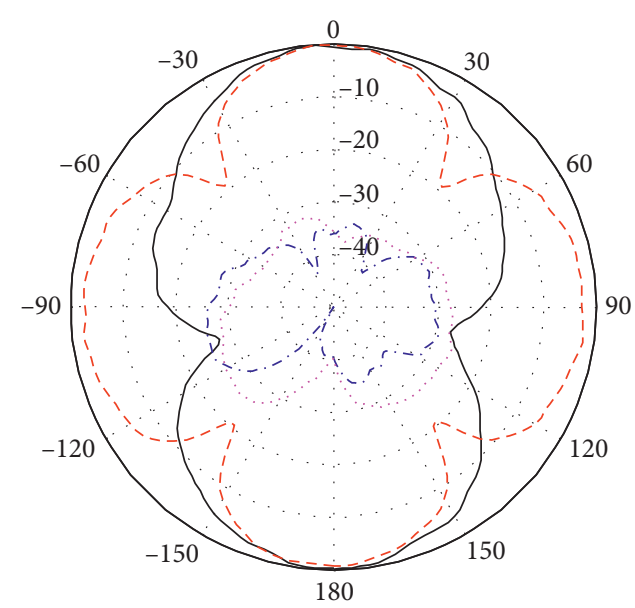

_ H-plane: co-pol. . -..- H-plane: cross-pol. - - E-plane: co-pol. ….. E-plane: cross-pol.

(b)

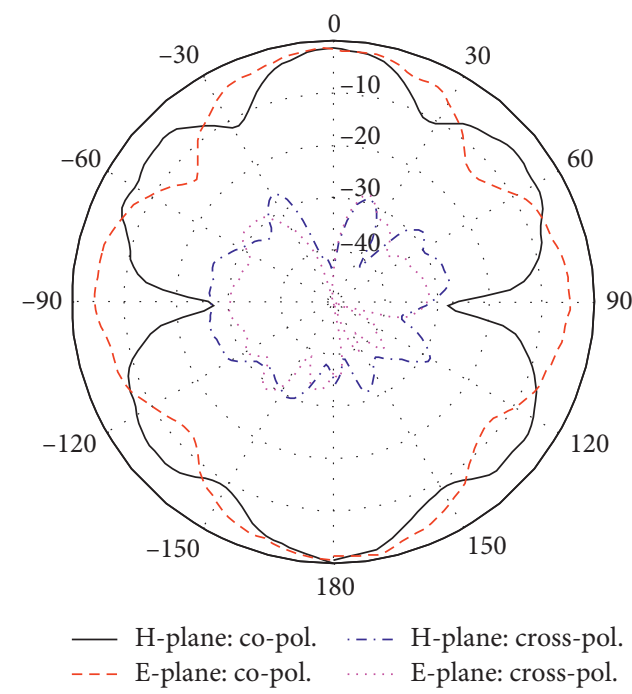

(c)

FIGURE 8: Radiation patterns of the proposed antenna array in the $\mathrm{H}$ - and E-planes at (a) 0.95 , (b) 1.85 , and (c) $2.45 \mathrm{GHz}$.

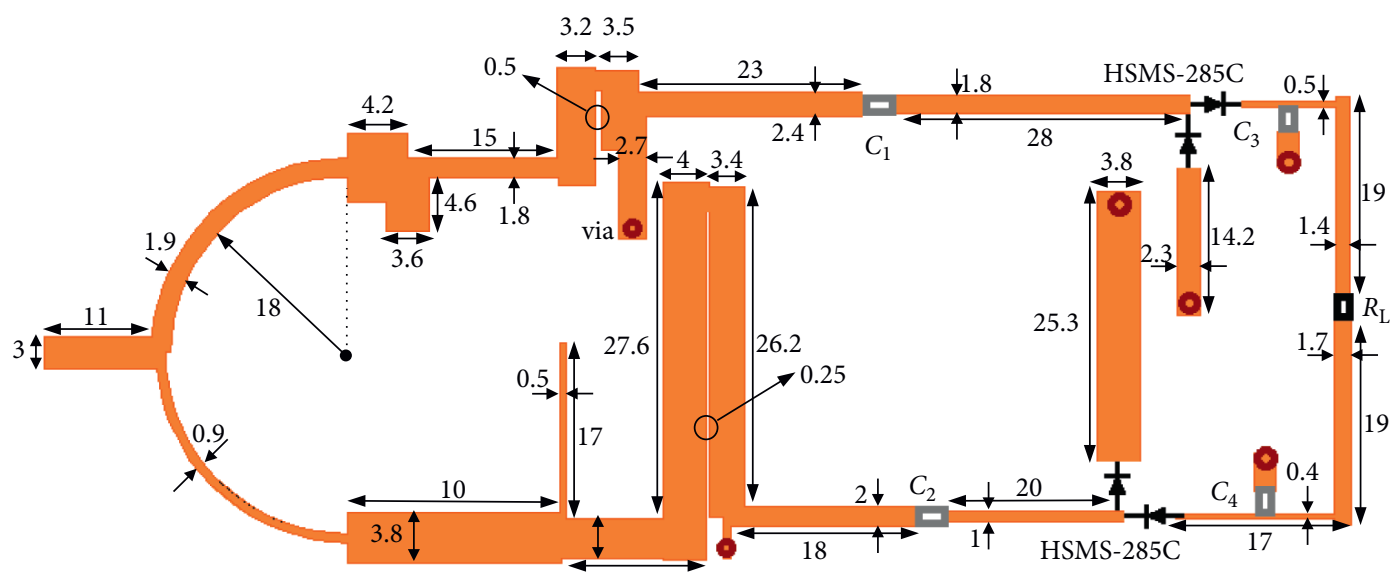

Figure 9: The schematic of the proposed rectifier: $C_{1}=C_{2}=330 \mathrm{pF}$ and $C_{3}=C_{4}=100 \mathrm{nF}$. 
of this scheme is that size of the impedance matching circuit is compact, because the circuit is designed on two different branches. With this two-branch impedance circuit, the rectifier can work as a function of input power level and frequency $[7,20]$. The upper branch is designed to acquire the circuit matched around 2.1 and $2.4 \mathrm{GHz}$, while the lower branch is designed to get the circuit matched around 0.9 and 1.8 GHz. As shown in Figure 9, capacitors $C_{1}$ and $C_{2}$ are part of the basic Greinacher rectifier circuit that can be considered as a DC-block for preventing the DC power from returning back to signal source. Meanwhile, capacitors $C_{3}$ and $C_{4}$ are used as DC-pass filter to smooth the output DC waveform and store the energy before the resistance load $R_{\mathrm{L}}$. The load $R_{\mathrm{L}}=4.7 \mathrm{k} \Omega$ is attached to the output port for collecting the DC power. The matching and rectifier circuits are simulated, analyzed, and optimized using Harmonic Balance (HB), Large Signal S-parameter (LSSP), and Momentum from Keysight Agilent ADS [33]. In order to improve the accuracy, a SPICE model for the Schottky diodes attained by the Avago Technology [31] is used in the simulation of the rectifier circuit. The chip capacitors in the design are also demonstrated using S-parameter files achieved by Murata.

The proposed rectifying circuit is designed on Rogers 4003 substrate with relative dielectric constant of 3.55 , thickness $h$ of $0.8 \mathrm{~mm}$, and $\tan \delta$ of 0.0027 . The rectifying circuit is optimized for the $-20 \mathrm{dBm}$ power input with input impedance of $38.1+19.5 j$ at $0.95 \mathrm{GHz}, 47.1+33.4 j$ at $1.85 \mathrm{GHz}, \quad 31.2+13.3 j$ at $2.15 \mathrm{GHz}$, and $36.5-2.7 j$ at $2.45 \mathrm{GHz}$.

The prototype of the proposed rectifier is shown in Figure 10 and it is measured in laboratory. The measured and simulated reflection coefficients $\left|S_{11}\right|$ of the designed rectifier for different input power levels, especially at lowpower levels, are exhibited in Figure 11. It can be seen that the proposed rectifier can cover the desired frequency band $\left(\left|S_{11}\right|<-10 \mathrm{~dB}\right)$ from 1.7 to $2.6 \mathrm{GHz}$ with an additional frequency around $0.9 \mathrm{GHz}$ band under three input power levels from -25 to $-15 \mathrm{dBm}$ with an interval of $5 \mathrm{dBm}$. The $S_{11}$ of the rectifier for three power levels is less than $-10 \mathrm{~dB}$ for the four center frequencies of interest. The simulated results have relatively good agreement with the measured ones, in which the minor discrepancies between them are almost because of the unknown parasitic behaviour of the SMD components applied in the rectifier circuit.

The RF-DC conversion efficiency of the rectifying circuit can be calculated as

$$
\eta(\%)=\frac{V_{\mathrm{DC}}^{2}}{P_{\mathrm{in}} R_{\mathrm{L}}} \times 100,
$$

where $V_{\mathrm{DC}}$ is the output DC voltage through the resistive load $R_{\mathrm{L}}$ and $P_{\text {in }}$ is the input power of the rectifying circuit.

The measured and simulated RF-DC conversion efficiency (with the optimal load $R_{\mathrm{L}}=4.7 \mathrm{k} \Omega$ ) for three input power levels versus operating frequency are depicted in Figure 12. As observed, it is found that the proposed rectifier operates well in a wide impedance bandwidth from 0.75 to $1.1 \mathrm{GHz}, 1.7$ to $2.1 \mathrm{GHz}$, and 1.3 to 2.7 in which the efficiency

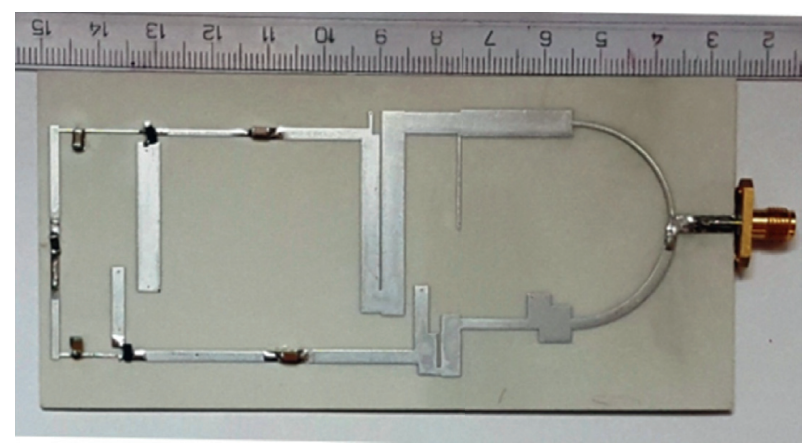

FIGURE 10: Photograph of the fabricated proposed rectifier.

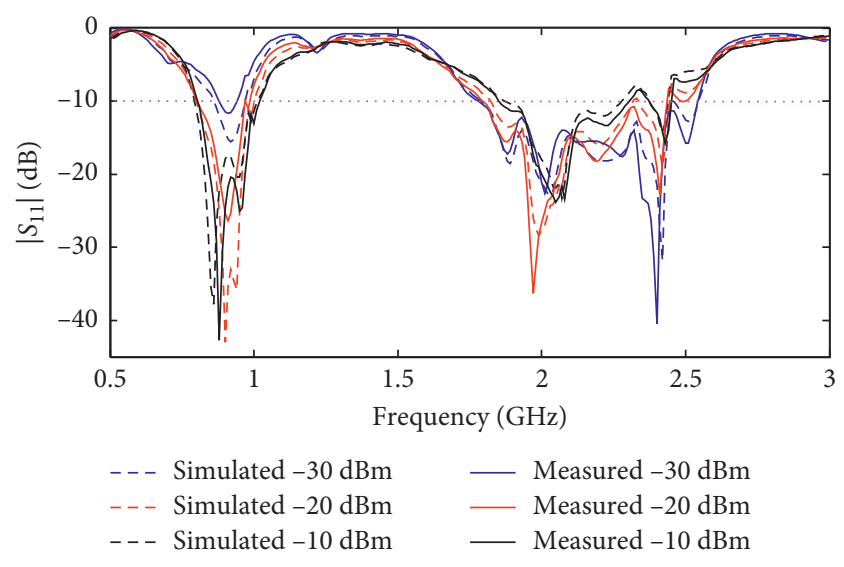

FIgURE 11: The measured and simulated $\left|S_{11}\right|$ of the proposed rectifier for three input power levels for the load resistance of $4.7 \mathrm{k} \Omega$.

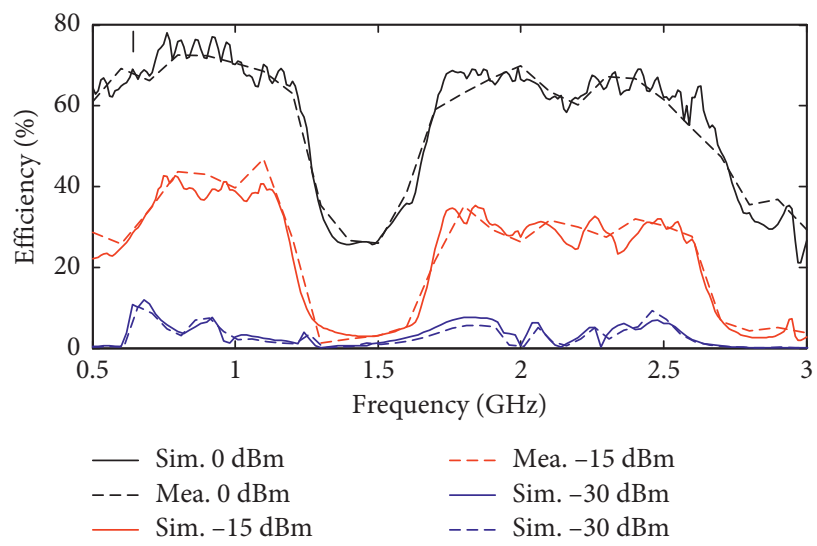

FIgURE 12: Simulated and measured efficiency of the rectifier vs. frequency at interest input power levels.

is still greater than $20 \%$ at the desired frequencies for input power levels over $-15 \mathrm{dBm}$. A small frequency shift occurs between the measured and simulated data, which is because of model inaccuracy of the diodes and the SMD components and fabrication tolerance.

The measured and simulated conversion efficiency at the four desired frequencies in terms of input power are shown in Figure 13. During the measurement, an RF signal 


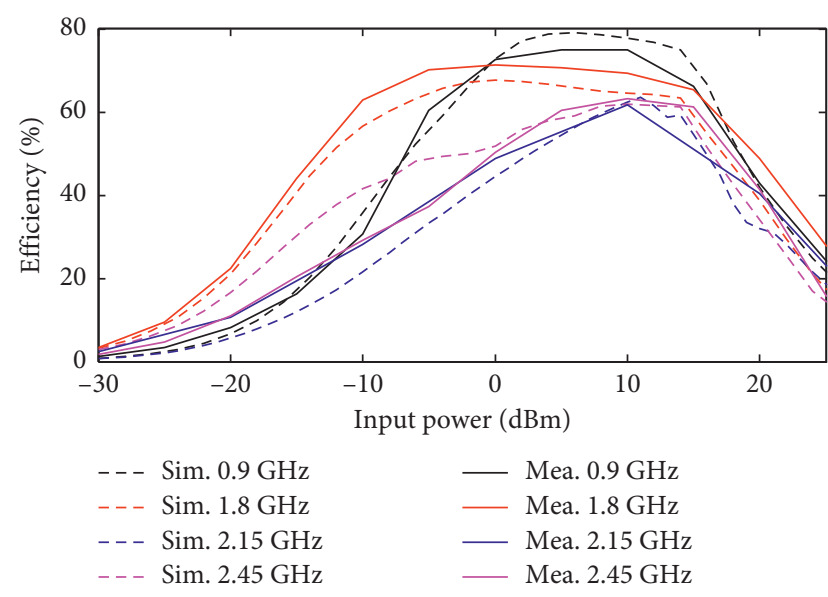

FIgURE 13: Simulated and measured efficiency of the rectifier vs. input power level at frequencies of interest.

generator is selected as the input source to the rectifier. The maximum efficiency at $0.9,1.8,2.15$, and $2.45 \mathrm{GHz}$ is around $76,71,61$, and $62 \%$ with $5,-5,10$, and $11 \mathrm{dBm}$ input, respectively. Compared with the simulated results, a minor error is observed, which could emerge by the manual welding process of the Schottky diode and chip capacitors.

Finally, the measured and simulated conversion efficiency of the simultaneous multiband input signals in terms of input power level are shown in Figure 14. Based on [4, 5], it is expected to enhance the overall RF-DC conversion efficiency of the rectifier compared to separate single band inputs. As shown in Figure 14, the proposed rectifier circuit for single, two, and three-band input signals is investigated. It can be seen that the maximum conversion efficiency is equal to $68 \%$ for low levels of power inputs when the proposed rectenna can receive three band signals simultaneously. In this case, the total RF-DC conversion efficiency enhancement is over $30 \%$ in the low levels of power that are working range of the designed rectifier.

\section{Wideband Rectenna Measurement}

The designed antenna and the rectifier are connected by a SMA connector with $50 \Omega$ characteristic impedance in order to make a rectenna. The measurement of the proposed wideband rectenna is presented in the following.

To verify the proposed wideband rectenna performance in a realistic measurement of the harvested power, first a spectrum analyzer is connected to the proposed array antenna for integrating the power spectrum over bandwidth. An indoor laboratory environment is selected with a relatively low ambient RF power density to demeanor the test. Nearest cell phone tower site is about $400 \mathrm{~m}$ away from the laboratory, while a Wi-Fi router is near the test location. The received power in $\mathrm{dBm}$ in terms of frequency is shown in Figure 15. It is clear that the power is mostly distributed at three frequency bands which are GSM-900, GSM-1800, and Wi-Fi with average power levels of $-42,-30$, and $-23 \mathrm{dBm}$, respectively. It should be noted that the measured overall power in the band received by antenna array is variable as a

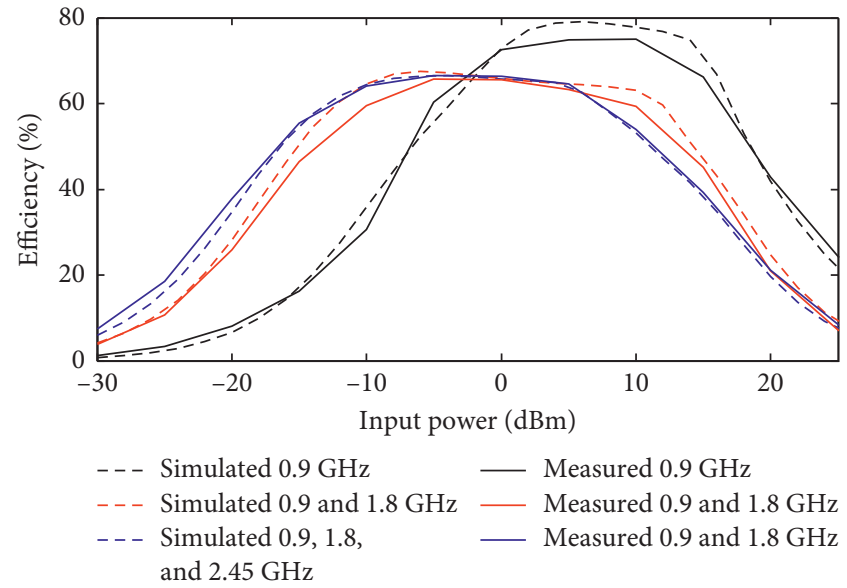

FIgURE 14: Simulated and measured conversion efficiency of the rectifier vs. input power level for multiband input signals.

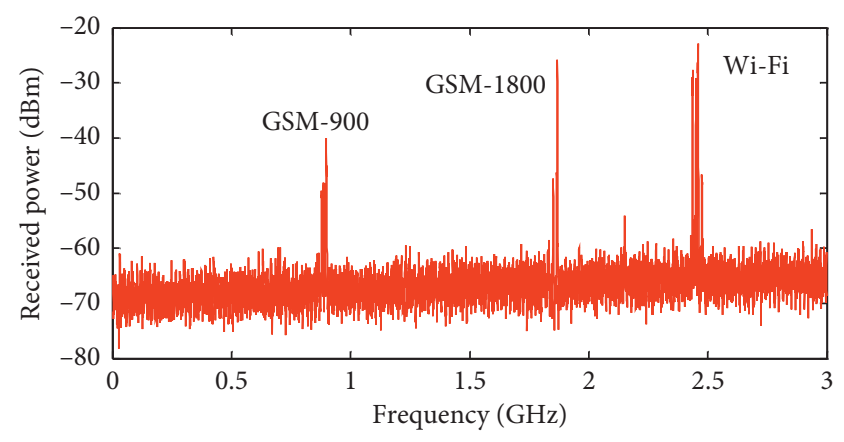

Figure 15: Measured power spectrum by the proposed antenna array inside the laboratory.

function of time. Second, the proposed antenna is substituted by the proposed rectenna and the DC output voltage is measured by using a voltage meter, as demonstrated in Figure 16. The output voltage is measured to vary around 160 to $250 \mathrm{mV}$ most of the time, and it could also reach over $250 \mathrm{mV}$ sometimes by reason of the change of ambient wireless energy, e.g., $243 \mathrm{mV}$ as shown in Figure 16. This voltage level can be absolutely used to run a low-power electronic device.

\section{Conclusions}

In this paper, a novel rectenna with wideband fractal antenna array and a wideband rectifier has been presented for ambient RF energy scavenging from $0.91 \mathrm{GHz}$ to $2.55 \mathrm{GHz}$. Antenna array with four monopole elements is proposed based on $2^{\text {nd }}$ iteration of Koch fractal geometry. A microstrip-to-slot-line transition feeding network has been used in the antenna array to guarantee the wideband operation and improve its performance, while a thin slot has been inserted in the monopole radiating patch to enhance the frequency bands and especially cover the higher band. By investigation of reflection coefficient, realized gain, and radiation characteristics, it is found that the proposed antenna can be most proper for harvesting. A wideband rectifying circuit using 


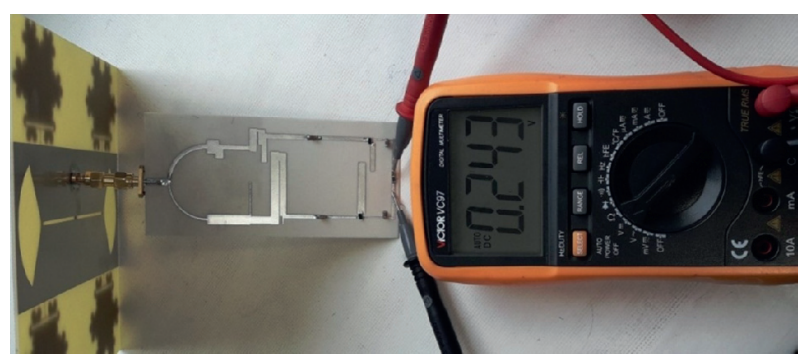

Figure 16: Rectenna measurement in a typical indoor laboratory ambience with a voltage meter.

two-branch matching circuits by applying an optimized coupled line and a full-wave rectifier circuit has been presented to match with the ambient wireless signals in the lowpower density. The measured and simulated results have shown that the rectifying circuit has maximum conversion efficiency of around $68 \%$ for $-10 \mathrm{dBm}$ input power at the four bands simultaneously. The proposed rectenna exhibits an output DC voltage between 160 and $250 \mathrm{mV}$ when measured in the indoor ambience. Considering the performance of the rectenna in various conditions, the presented design is appropriate for many low-power electronic devices and can be used in many wireless applications without a battery.

\section{Data Availability}

The data required to replicate the proposed structures and support the conclusions are illustrated in the figures and pictures. Also, for more aid, the readers can contact the author by e-mail through mmfakharian@ugsr.ir.

\section{Conflicts of Interest}

The author declares that he has no conflicts of interest.

\section{Acknowledgments}

The author gratefully acknowledges experimental support by the Sharif Center for Laboratory Services (Center Lab) at Sharif University of Technology and Antenna Laboratory at Iran Telecommunication Research Center (ITRC). This research was also supported by Iran's National Elites Foundation (INEF).

\section{References}

[1] S. Kim, R. Vyas, J. Bito et al., “Ambient RF energy-harvesting technologies for self-sustainable standalone wireless sensor platforms," Proceedings of the IEEE, vol. 102, no. 11, pp. 1649-1666, 2014.

[2] M. Pinuela, P. D. Mitcheson, and S. Lucyszyn, "Ambient RF energy harvesting in urban and semi-urban environments," IEEE Transactions on Microwave Theory and Techniques, vol. 61, no. 7, pp. 2715-2726, 2013.

[3] J. A. Hagerty, F. B. Helmbrecht, W. H. McCalpin, R. Zane, and Z. B. Popovic, "Recycling ambient microwave energy with broad-band rectenna arrays," IEEE Transactions on
Microwave Theory and Techniques, vol. 52, no. 3, pp. 10141024, 2004.

[4] V. Helmbrecht, C. Lahuec, F. Seguin, and C. Person, "A multiband stacked RF energy harvester with RF-to-DC efficiency up to 84\%," IEEE Transactions on Microwave Theory and Techniques, vol. 63, no. 5, pp. 1768-1778, 2015.

[5] C. Song, Y. Huang, P. Carter et al., "A novel six-band dual CP rectenna using improved impedance matching technique for ambient RF energy harvesting," IEEE Transactions on Antennas and Propagation, vol. 64, no. 7, pp. 3160-3171, 2016.

[6] M. Zhou, M. Shojaei Baghini, and G. Kumar, "Broadband bent triangular omnidirectional antenna for RF energy harvesting," IEEE Antennas and Wireless Propagation Letters, vol. 15, pp. 36-39, 2016.

[7] C. Song, Y. Huang, J. Zhou, J. Zhang, S. Yuan, and P. Carter, "A high-efficiency broadband rectenna for ambient wireless energy harvesting," IEEE Transactions on Antennas and Propagation, vol. 63, no. 8, pp. 3486-3495, 2015.

[8] H. Mahfoudi, M. Tellache, and H. Takhedmit, "A wideband rectifier array on dualpolarized differential-feed fractal slotted ground antenna for RF energy harvesting," International Journal of RF and Microwave Computer-Aided Engineering, vol. 29, no. 8, Article ID e21775, 2019.

[9] M. Mansour, X. Le Polozec, and H. Kanaya, "Enhanced broadband RF differential rectifier integrated with archimedean spiral antenna for wireless energy harvesting applications," Sensors, vol. 19, no. 3, p. 655, 2019.

[10] T. S. Almoneef, H. Sun, and O. M. Ramahi, "A 3-D folded dipole antenna array for far-field electromagnetic energy transfer," IEEE Antennas and Wireless Propagation Letters, vol. 15, pp. 1406-1409, 2016.

[11] A. Reyna, M. A. Panduro, and L. I. Balderas, "A wideband rectenna array for RF energy harvesting applications," in Proceedings of the 12th European Conference on Antennas and Propagation, p. 3, London, UK, April 2018.

[12] A. Alex-Amor, J. M. Fernández-González, P. Padilla, and M. Sierra-Castañer, "Comparison between a multiband PIFA and a ultrawideband Archimedean spiral antenna for energy harvesting in microwave bands," in Proceedings of the 2nd URSI Atlantic Radio Science Meeting (AT-RASC), pp. 1-4, Meloneras, December 2018.

[13] C. Song, Y. Huang, J. Zhou et al., "network elimination in broadband rectennas for high-efficiency wireless power transfer and energy harvesting," IEEE Transactions on Industrial Electronics, vol. 64, no. 5, pp. 3950-3961, 2017.

[14] A. Kumar, S. Sinha, A. Sepahvand, and K. K. Afridi, "Improved design optimization for high efficiency matching networks," IEEE Transactions on Power Electronics, vol. 33, no. 1, pp. 37-50, 2018.

[15] S. Chandravanshi and M. J. Akhtar, "Design of efficient rectifier using IDC and harmonic rejection filter in GSM/ CDMA band for RF energy harvesting," Microwave and Optical Technology Letters, vol. 59, no. 3, pp. 681-686, 2017.

[16] Z. Ma and G. A. E. Vandenbosch, "Wideband harmonic rejection filtenna for wireless power transfer," IEEE Transactions on Antennas and Propagation, vol. 62, no. 1, pp. 371-377, 2014.

[17] M. M. Mansour and H. Kanaya, "Compact and broadband RF rectifier with 1.5 octave bandwidth based on a simple pair of L-section matching network," IEEE Microwave and Wireless Components Letters, vol. 28, no. 4, pp. 335-337, 2018.

[18] P. Wu, S. Y. Huang, W. Zhou, and C. Liu, "One octave bandwidth rectifier with a frequency selective diode array," 
IEEE Microwave and Wireless Components Letters, vol. 28, no. 11, 2018.

[19] L.-F. Li, X. Yang, and E.-J. Liu, "A broadband high-efficiency rectifier based on two-level impedance match network," Progress in Electromagnetics Research Letters, vol. 72, pp. 91-97, 2018.

[20] Y. L. Lin, X. Y. Zhang, Z.-X. Du, and Q. W. Lin, "High-efficiency microwave rectifier with extended operating bandwidth," IEEE Transactions on Circuits and Systems II: Express Briefs, vol. 65, no. 7, pp. 819-823, 2018.

[21] D. Zhai, C. Zhang, Z. Yang, and S. Hu, "Design of the antenna array with a novel feeding network," in Proceedings of the 2012 International Conference on Microwave and Millimeter Wave Technology (ICMMT), pp. 1-4, Shenzhen, China, 2012.

[22] C.-X. Zhang, Y.-Q. Zhuang, X.-K. Zhang, and L. Hu, "An UWB microstrip antenna array with novel corporate-fed structure," Progress in Electromagnetics Research C, vol. 52, pp. 7-12, 2014.

[23] D. D. Krishna, M. Gopikrishna, C. K. Aanandan, P. Mohanan, and K. Vasudevan, "Compact wideband Koch fractal printed slot antenna," IET Microwaves, Antennas \& Propagation, vol. 3, no. 5, pp. 782-789, 2009.

[24] M. M. Fakharian and P. Rezaei, "Parametric study of UC-PBG structure in terms of simultaneous AMC and EBG Properties and its applications in proximity-coupled fractal patch antenna," International Journal of Engineering-Transactions A: Basics, vol. 25, no. 4, p. 347, 2012.

[25] M. M. Fakharian, P. Rezaei, and A. A. Orouji, “A novel slot antenna with reconfigurable meander-slot DGS for cognitive radio applications," Applied Computational Electromagnetics Society Journal, vol. 30, no. 7, pp. 748-753, 2015.

[26] Ansoft HFSS v. 13.0: Ansoft Inc., Pittsburgh, PA, USA, 2011.

[27] K. Q. da Costa and V. Dmitriev, "Theoretical analysis of a modified Koch monopole with reduced dimensions," IEE Proceedings-Microwaves, Antennas and Propagation, vol. 153, no. 5, 2006.

[28] K. Egashira, E. Nishiyama, and M. Aikawa, "Planar array antenna using both-sided MIC's feeder circuits," Electronics and Communications in Japan (Part I: Communications), vol. 87, no. 7, pp. 23-30, 2004.

[29] M. M. Zinieris, R. Sloan, and L. E. Davis, "A broadband microstripto-slot-line transition," Microwave and Optical Technology Letters, vol. 18, no. 5, 1998.

[30] C. R. Valenta and G. D. Durgin, "Harvesting wireless power: survey of energy-harvester conversion efficiency in far-field, wireless power transfer systems," IEEE Microwave Magazine, vol. 15, no. 4, pp. 108-120, 2014.

[31] Non RF Applications for Surface Mount Schottky Diode Pairs HSMS285x, Datasheet, Avago Technol., San Jose, CA, USA, May 2010.

[32] U. Olgun, J. L. Volakis, and C.-C. Chen, "Design of an efficient ambient WiFi energy harvesting system," IET Microwaves, Antennas \& Propagation, vol. 6, no. 11, pp. 1200-1206, 2012.

[33] The advanced design system (ADS), Agilent Corp., 2009. 